\title{
Shikakeology: designing triggers for behavior change
}

\author{
Naohiro Matsumura • Renate Fruchter • \\ Larry Leifer
}

Received: 30 November 2013/ Accepted: 21 August 2014/Published online: 7 October 2014

(c) The Author(s) 2014. This article is published with open access at Springerlink.com

\begin{abstract}
A shikake is an embodied trigger for behavior change to solve social or personal problems. In this paper, we first present a general statement regarding the concept of Shikakeology as the science of shikake. The mechanism behind a shikake covers a wide range of physical and psychological triggers. From a shikake perspective, physical triggers are used to ignite psychological triggers, and psychological triggers work as driving forces for changing behavior. We use a case study approach to explain the shikake mechanism. We describe five simple cases to explain the concept of shikake as well as their trigger mechanisms. We then present shikake trigger categories, which are used to systematically describe shikake triggers. To date, we have annotated 120 shikake cases according to these categories. To explore rules of thumb for the shikake triggers, we finally present the statistics as a shikake trigger matrix to represent patterns of triggers frequently used together.
\end{abstract}

N. Matsumura $(\square)$

Graduate School of Economics, Osaka University, 1-7

Machikaneyama, Osaka 650-0043, Japan

e-mail: matumura@econ.osaka-u.ac.jp

R. Fruchter

Department of Civil and Environmental Engineering, Stanford University, Yang and Yamasaki Environment and Energy Building (Y2E2), 473 Via Ortega, Stanford, CA 94305-4020, USA

e-mail: fruchter@stanford.edu

\section{Leifer}

Department of Mechanical Engineering, Stanford University, Building 560, 424 Panama Mall, Stanford, CA 94305-2232, USA

e-mail: leifer@cdr.stanford.edu
Keywords Shikakeology $\cdot$ Shikake $\cdot$ Behavior design

\section{Introduction}

1.1 The strength of a small trigger

It is often the case that a small trigger can change our behavior and result in a big social impact (Andrews 2010). A famous example is the fly target etched on urinals in men's restrooms at Schiphol Airport in Amsterdam (discussed in Sect. 4.3). When men see the fly target, their behavior is expected to change due to the temptation to aim at the fly. The fly target in urinals is a small trigger that causes a slight behavior change, but it is reported that spillage was reduced by $80 \%$ (Thaler and Sunstein 2009). This eventually reduces cleaning expenses and water usage. Consequently, it had a broader impact on reducing environmental pollution. There are several examples of the "small trigger causing a big difference" phenomenon at the personal level, such as increased exercise and healthier eating. These also manifest in pro-social behavior at the government level (e.g., reducing garbage, waste foods, traffic accidents, and crime).

\subsection{The concept of "shikake"}

"Shikake" is a Japanese word with various meanings, depending on the context. According to Shogakukan's Progressive Japanese-English Dictionary, shikake means "a device, mechanism, contrivance, and system" as a noun and "to start, set up, prepare, and challenge" as a verb. In this paper, we use "shikake" as a complex integration of these definitions to describe an approach to trigger behavioral changes that will solve social or personal problems. As the 

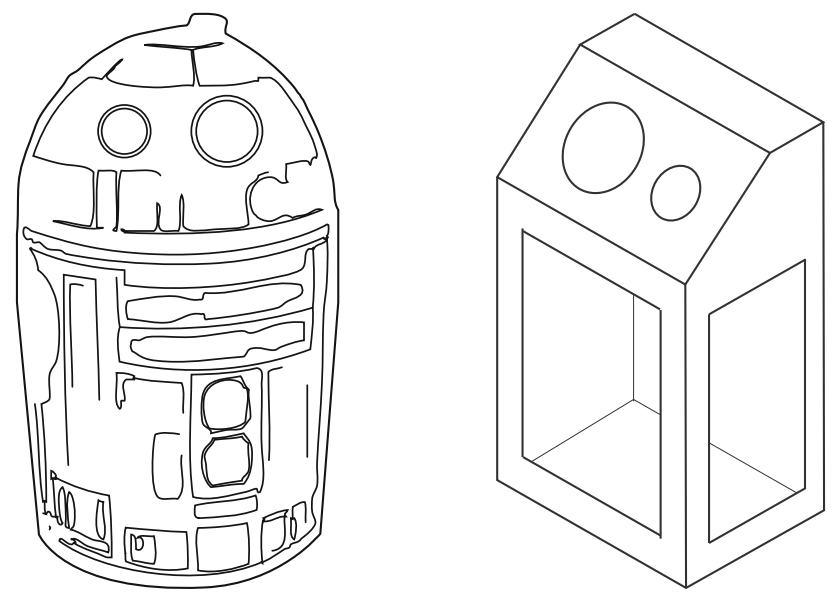

Fig. 1 High-tech trash bin and transparent trash bin

problems that we are targeting result from our own behavior, changing behavior is a straightforward approach to solve them. The aim of a shikake approach was to solve a problem through behavior, not through function. This is the most unique and significant aspect of the shikake approach.

In contrast to the shikake-driven approach, one might consider a high-tech device that automatically solves problems without people's help. However, such a hightech-driven approach is feasible if and only if the device can be created. Practically, this is not a realistic choice in most cases, as it requires considerable effort in terms of fabrication cost, expertise, and technology.

Let us consider a simple example of garbage separation. Figure 1 shows a trash bin with a built-in high-tech device that can automatically separate plastic bottles and cans, and a trash bin with a transparent structure. The transparent trash bin does not seem particularly special, but it encourages people to separate bottles and cans more than a normal, nontransparent trash bin would (IPROS 2004). The items that people throw away are visible to others with a transparent trash bin. This elicits pro-social behavior because people do not want lose face and thereby have their self-esteem compromised. In addition, the garbage in the transparent trash bin becomes a social norm indicating that people have correctly separated their trash. Deviations from the social norm require special circumstances. In this case, the transparency of a trash bin becomes an effective shikake to make people aware of their behavior.

Human behavior is superior to the functionality of current high-tech devices; that is, in terms of vision, operation, and mobility, our eyes, feet, and hands are superior to computer vision, robot hands, and wheels at recognizing objects, moving to a destination, and interacting with objects under various environments. Thanks to these human capabilities, social and personal problems can be solved through behavioral changes. In fact, the Central Japan Railway Company has already replaced about 1,600 ordinary trash bins with transparent trash bins. Thus, the shikake-driven approach is far more feasible and effective choice.

This paper aims to provide a general statement on the concept of Shikakeology as a science of shikake in order to understand the underlying mechanisms. In the following sections, we first define the meaning of shikake in the study of Shikakeology. We then introduce the mechanisms of behavior change from precedence studies, followed by concrete shikake cases. We then explain the patterns of best practices, shikake triggers, and shikake trigger matrix in turn. We finally conclude this paper with future work.

\section{Shikake definition}

The original meaning of shikake is ambiguous as a technical term. In the context of Shikakeology, we define a shikake to include the following three characteristics:

1. A shikake is an embodied trigger for behavior change.

2. The trigger is designed to induce a specific behavior.

3. The behavior solves a social or personal problem.

A shikake should be practical rather than academic or theoretical. That is why we emphasize "embodied trigger" to distinguish it from the ambiguous usage of "trigger," as indicated in the first characteristic. Here, we consider an embodied trigger as an artifact that is perceivable and desirable. In addition, a shikake is not a trap to force or trick people, but a way to encourage people to change their behavior by presenting them with possible alternative behaviors, either explicitly or implicitly. The alternative behavior needs to be carefully designed because the induced behavior becomes an approach to the problem to be solved. That is why we emphasize "specific behavior" in the second characteristic and "social or personal problem" in the third characteristic.

One important point is that the objectives of target people and shikake designers do not necessarily align. In the trash bin example mentioned in the previous section, the objective of target people is to "not lose face" by deviating from a social proof (i.e., copying the actions of others in order to behave in socially acceptable way). On the other hand, the objective of the designer is to improve the accuracy of garbage separation. These objectives do not match; nevertheless, the shikake solves the problem.

\section{Psychological and physical triggers}

A shikake has two aspects: a psychological trigger and a physical trigger. A good combination of these two types of triggers leads to an effective shikake to change people's behavior. 


\subsection{Psychological triggers}

Psychological triggers affect our psychological preference. The power of social pressure has been investigated for decades, primarily in experimental settings. Asch (1955) conducted experiments in visual judgment and revealed that social forces easily alter people's opinions. Milgram et al. (1969) also reported that conformity increases as a function of group size through experimental results that more people in a crowd looking up at a building let to more passersby joining the crowd. Cialdini (2006) described in his book the way in which people are influenced and, as a result, persuaded. He categorized various cases regarding behavior change into six main factors: reciprocity, authority, social proof, commitment and consistency, liking, and scarcity. Thaler and Sunstein (2009) described in their book "Nudge" the way in which people can be nudged to make the world better, especially in terms of health, wealth, and happiness. They explained various cases in accordance with six principles of good choice architecture: incentives, understanding mappings, defaults, give feedback, expect error, and structure complex choices. Fogg's (2009) behavior model explained that three elements (motivation, ability, and trigger) must converge simultaneously for a behavior to occur. In his model, a trigger that is a reminder of a habitually associated action should be designed first. If the trigger does not work, six ability factors should be tackled next, namely, time, money, physical effort, brain cycles, social deviance, and nonroutine. If these factors do not work, the final approach is motivation. Fogg (2002) also proposed an approach for persuasion using a computer and revealed persuasive techniques in the domain of software applications and mobile devices. Zichermann and Cunningham (2011) described game mechanics as a technique to encourage people to become involved in activities. Game mechanics stimulate human desires for reward, status, achievement, self-expression, competition, and altruism, and so forth by designing a system that controls points, badges, levels, challenges, leaderboards, goods, quests, etc.

\subsection{Physical triggers}

Physical triggers work directly and indirectly. As a direct effect, a physical trigger is realized by good visibility of function that enables people to understand intuitively the usage and expected results. For example, a door with good visibility of function tells people (1) opened or closed, (2) locked or unlocked, and (3) push or pull or slide right/left/ up/down. If these functions are obscure, the visibility is inadequate and needs to be improved. A shikake should have good visibility because it has to induce the appropriate behavior. Such a perceived function, which enables people to perform an action, was termed "affordance" by Norman (2002). He later revised the term as "perceived affordance" or "signifier" instead of "affordance" to make the vocabulary more precise; a perceived affordance is some signal in the physical and social world that can be interpreted meaningfully (Norman 2010). Sullivan (1896) proposed a principle known as "form follows function," where the shape of an object reveals the purpose of the object. The concept was first applied to architecture and then spread to other design fields, such as product design and automobile design. The principle is also considered a direct physical trigger.

A physical trigger has an indirect effect on behavior, in that it activates a psychological trigger. For example, the transparent trash bin works as a physical trigger to cause senses of social proof and thereby changes in self-esteem. In this case, these feelings work as psychological triggers ignited by the physical trigger.

\subsection{Psychological and physical triggers}

Volkswagen introduced the idea "Fun can change behavior for the better," developing various products that change behavior to solve social problems. For example, The World's Deepest Bin makes a long falling sound as if the bottom of the bin was deep underground when garbage is thrown into it (Volkswagen 2009). The sound attracts people's attention, and as a result, more garbage is expected to be collected by people who observe this feedback and have fun trying it repeatedly. The concept of The Fun Theory emphasizes that "fun" is the most powerful driving force to change behavior for the better. The "fun" products are created by way of physical and psychological triggers.

\subsection{Challenges for Shikakeology}

As described above, psychological triggers are categorized differently - as persuasion, engagement, nudges, human factors, and biases-in accordance with different perspectives, in order to best describe the fundamental mechanism. Physical triggers are also considered in various ways, such as perceived affordance (or signifier), feedback, and technologies, to specify the component of a trigger. Furthermore, a physical trigger is associated with a psychological trigger, and that, specifically, is what a shikake focuses on, as the combination works strongly to facilitate behavior change.

From a shikake point of view, categories of psychological and physical triggers should be optimized to describe the fundamental mechanism. However, the criteria have not yet been studied. One of the biggest challenges in the establishment of Shikakeology is to uncover the criteria 
for categories best tailored to describe shikake specifications. These categories are useful not only to understand the mechanism of shikake specifications but also to design new shikakes. Currently, we are collecting hundreds of shikake cases to identify these categories. The preliminary shikake categories, extracted from 120 shikake cases, will be presented later in this paper.

\section{Shikake cases and mechanisms}

The mechanism behind shikake cases covers a wide range of physical and psychological triggers. A physical trigger is used to ignite a psychological trigger, and the psychological trigger works as a driving force for changing behavior. In this section, we will show five simple shikake cases to clarify the concept of shikake as well as the mechanisms by which triggers function.

\subsection{Cylinder}

Figure 2 is a cylinder installed at Tennouji Zoo in Japan. There is no explanation board around it. People are not told what this artifact is, but they can guess how to use it because it has some triggers. First, the cylinder looks like a telescope, so people might imagine that one looks through it. Second, there is a hole in the cylinder. When people find the hole, they instinctively look through it out of curiosity. Third, the cylinder is placed about one meter off the ground. The position is ideal for children to look inside the hole. Because of these triggers, children are interested in the cylinder, approach the cylinder, look inside the cylinder, discover something at the other end of the cylinder, and finally enjoy the discovery. In this case, children find a replica of an elephant's excrement and are surprized to notice the size and color.

When people observe a child's behavior for a while, they might notice that once he/she looks inside the cylinder, the behavior attracts other children's attention and makes them gather around the cylinder. This phenomenon is called as snowball effect, where a small action becomes a trigger that leads to a big effect. As a result, the cylinder succeeds in attracting children and triggers their interest to explore and discover.

The cylinders are installed along the pathway connecting the animal exhibition areas. If there were no cylinders, children would not stop walking to explore and discover. In addition, the cylinder is easy to make but difficult to break due to its simple structure. All things considered, the cylinder works as a superb shikake for behavior change.

The telescope-like shape and the installation height of the cylinder work as physical triggers for people to infer its utility and attract target people (i.e., children). The hole in

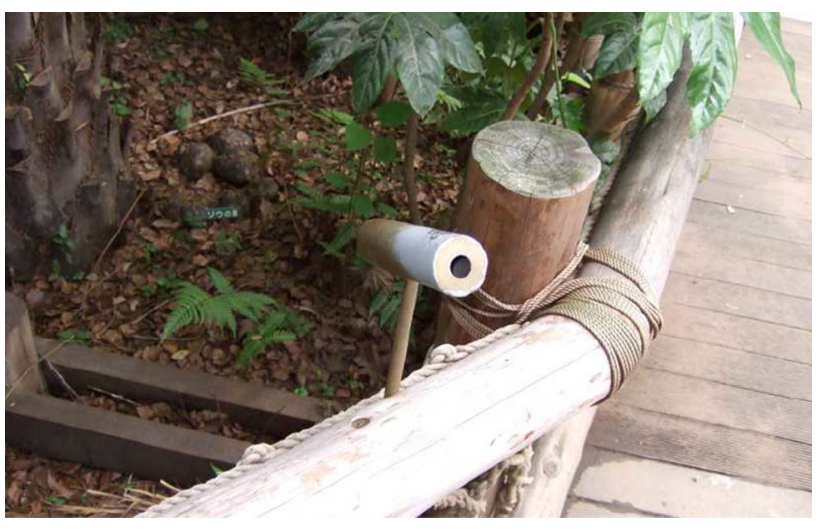

Fig. 2 Cylinder

the cylinder works as a physical trigger to induce a specific behavior as well as a psychological trigger to excite curiosity. In addition, people looking into the cylinder could act as a psychological trigger for a snowball effect. In this case, the analogy of a telescope, perceived affordance of a hole, curiosity, and social effect are considered the underlying mechanisms of the cylinder on the zoo pathway.

\subsection{Tiny shrine gate}

Littering is an everyday problem that all societies have in common, and its underlying mechanisms have been studied. The broken windows theory hypothesizes that a small trigger causes a big result, like a snowball effect (Wilson and Kelling 1982). If there is a broken window in a building, the window becomes a sign of disorder and leads to more broken windows. The same is true for littering (Keizer et al. 2008). If someone drops one piece of litter, the litter becomes a trigger to induce more littering. Complete cleanliness would likely be a good trigger to stop littering, but it is not a realistic solution due to its high cost.

Figure 3 shows a tiny replica of a gate to a Shinto shrine. The tiny shrine gate reminds people of a holy place, and this prevents them from littering. This shikake also prevents bad behavior, such as dog walkers not picking up excrement. In this case, the shikake works if and only if people associate the tiny shrine gate with a Shinto shrine.

Other approaches, such as putting up anti-littering signs or installing high-tech devices like security cameras, are possible. However, these approaches give neighbors a descriptive norm of caution and compromise the trusting atmosphere. In contrast, the tiny shrine gate provides an elegant and simple approach that does not negatively affect the atmosphere.

The shrine gate is a physical object, but it works as a psychological trigger to cause pro-social behavior by giving the impression of a holy place. In this case, the analogy of a shrine gate and the associated social norm are 


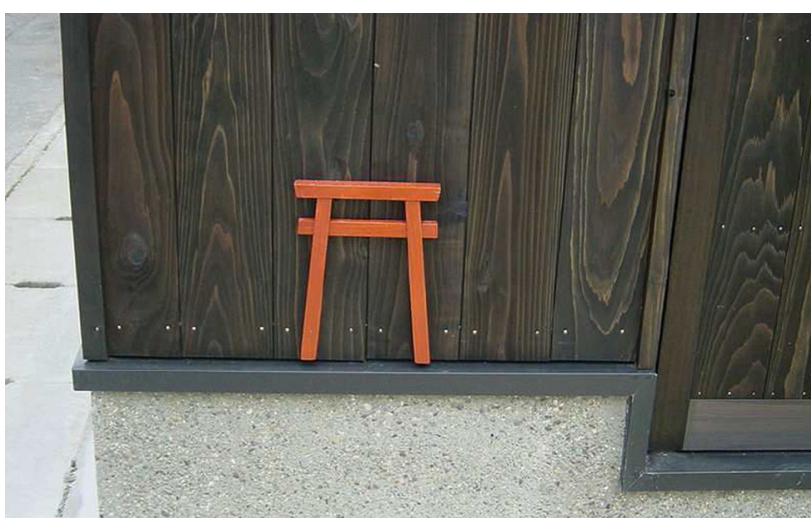

Fig. 3 Tiny shrine gate

considered the underlying mechanisms. In other words, this shikake might not work in places where nobody understands the symbol and respective behavior associated with shrine gates. Therefore, this shikake is culturally dependent. Culture could be a strong trigger when considering the use of social norms, but we must carefully account for the potential sensitivities in order to avoid provoking people's adverse reactions.

\subsection{Urinal fly}

Figure 4 shows a fake fly etched on a urinal. Once people (men in this case) see the fly, they instinctively aim at it. The location and type of target are designed to determine the "sweet spot" and thus minimize splash back (Smets 1995). As a result, spillage is expected to reduce and thereby increase the cleanliness of the facility. We do not need any reason to aim at the fly aside from the fun. We do not have to aim at it, but there is no reason we should not. Due to the effectiveness of the idea and the simplicity of its implementation, various urinal target stickers, such as

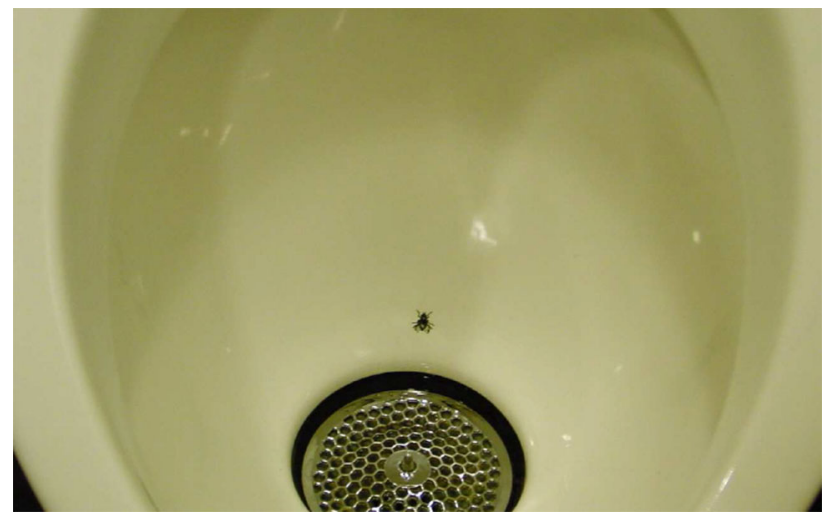

Fig. 4 Urinal fly (Broennimann 2010)

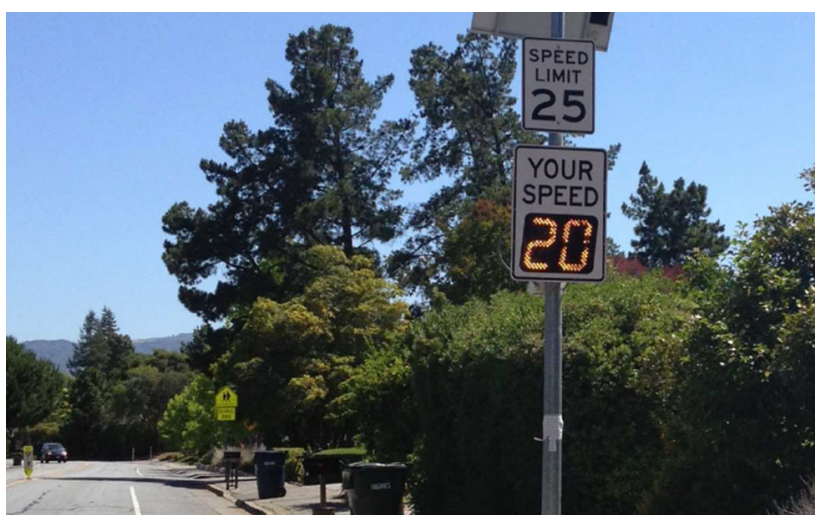

Fig. 5 Speed camera

a bee, a dartboard, and a flame (the color changes with temperature change), are now used worldwide.

A urinal fly has the physical shape of a fly and causes a psychological trigger to aim at it by instinct. In this case, the analogy of a fly for the target and the playful challenge of hitting the target are considered the underlying mechanisms.

\subsection{Speed camera}

Cars are convenient for transportation, but every year many people are injured or killed in traffic accidents. Various shikakes have been considered to make traffic safer. Figure 5 shows a speed camera that feeds back the speed of a car with a speed limit sign. This system is not connected to a police office, so there is no force compelling drivers to slow down. However, this system works well in practice. The feedback of cars' speed to the drivers becomes a good trigger to change from mindless to mindful driving.

In addition to feeding back the speed, one more shikake element could be added. The Speed Camera Lottery is a campaign in which the speed of passing cars is monitored, and lottery prizes are randomly mailed to the houses of drivers who maintained their speed under the limit (Volkswagen 2009). The reward comes from speeding fines. As a result, the average speed was reportedly reduced by $22 \%$ when the Speed Camera Lottery was tested in Sweden.

A physical speed camera produces feedback and thereby ignites a psychological trigger to control speed. In addition, the lottery system works as a psychological trigger for driving to obtain a reward. Furthermore, when a goal is clearly provided, it becomes a challenge. In this case, feedback to car drivers to reduce their speed, and the challenge to keep under the speed limit using rewards worked as the underlying mechanisms.

Unlike the other cases, this case uses electronic technology. A shikake does not necessarily depend on 


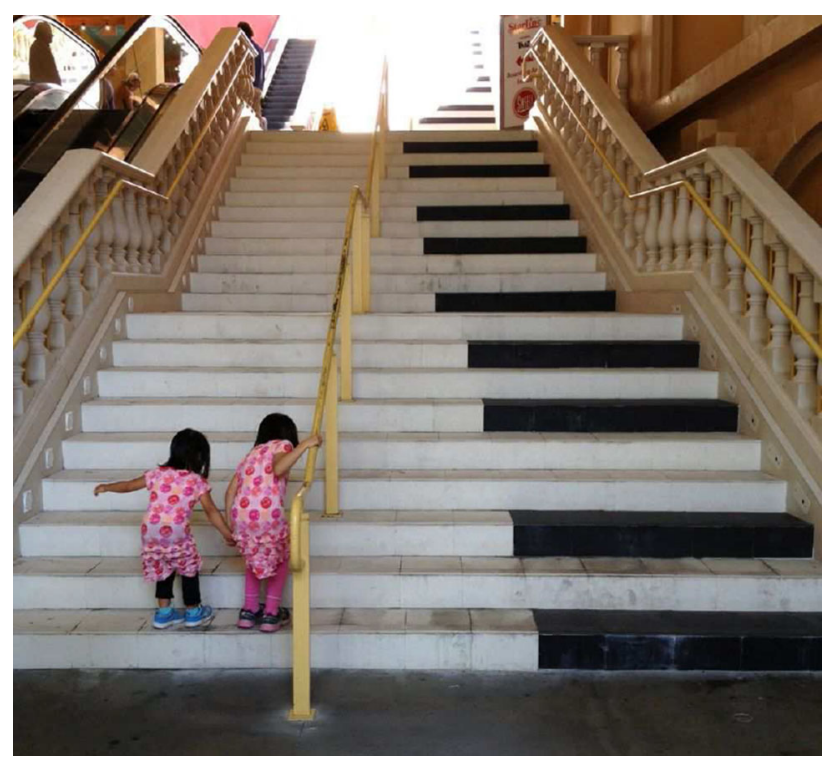

Fig. 6 Piano stairs in Hollywood

technology because it heightens the efforts needed to make it due to cost and required expertise. However, when it becomes possible to use technology and it generates a synergistic effect, a technology-based trigger becomes a powerful shikake toward behavior change.

\subsection{Piano stairs}

Figure 6 shows the stairs decorated like a piano, on which people can actually make a piano-like sound with their feet instead of their fingers. The stairs attract people's attention and encourage them to use the stairs rather than escalators. As a result, more people are willing to exercise. According to a report on The Fun Theory, ${ }^{1}$ the number of people who used the stairs increased by $66 \%$. The point in this case is that no one was forced to use the stairs. Those who were interested in the piano stairs voluntarily chose to use the stairs.

The piano-like appearance allows people to easily associate the stairs with a piano and to have a pleasant experience playing the piano or listening to music. This psychological association between a piano and an enjoyable experience is the core trigger to drive people to use the stairs. This shikake is implemented using technologies (e.g., sensor devices and sound devices). Thus, the shikake is realized as a combination of design, psychology, and technologies.

$\overline{1}$ http://www.thefuntheory.com.

\section{Patterns of best practices}

\subsection{Utility of patterns}

Lessons from best practices could be a promising approach for success or reducing the risk of failure because they give us cues for future prediction as well as estimations of necessary efforts. Of course, best practices depend on the situations, and the same practices cannot be applied across all situations. However, it might be applicable to similar situations if the pattern can be generalized and applicable to a broad range of situations. Patterns are also used to bridge the gap between people in various domains. Common knowledge for an expert in one domain is unknown to people in other domains. A pattern is considered a simple expression of essential knowledge in a specific domain that allows people to share it.

Patterns, which are obtained from knowledge and procedures of best practices, are used to increase the utility of people's activities. In the following, we briefly review some ideas of useful patterns in practice in both cases.

\subsection{Patterns from knowledge}

Alexander et al. (1977) coined the term "Pattern Language" to express a new methodology where a pattern as a unit of best practice is combined with other patterns for designing architecture and surroundings. Pattern Language is described in a unified format, such as pattern name, picture or sketch, explanation, and relations with other patterns. Alexander created 253 patterns for describing good design practices and applied them to various design projects. Gamma et al. (1994) proposed "Design Patterns" as a programming approach based on the elements of reusable object-oriented codes. They proposed 23 patterns of codes as a general reusable solution. By combining the patterns, the manners of code are formalized and the generated code becomes more efficient and readable. A pattern language works as a common terminology between people in an interdisciplinary field. Borchers (2008) presented an approach for applying pattern language to interaction design in order to facilitate cooperation between developers and domain experts. The pattern language obtained from good practices can also be used to teach humancomputer interaction. User interface patterns are widely used on websites or desktop applications (Tidwell 2011). Software libraries for designing user interfaces are provided as a toolkit, making it possible to reuse the best practices of user interface for solving design problems. Content management systems such as WordPress or Wiki are also considered as applications of user interface patterns because they publish contents with a standardized format based on the patterns of best practices. Hatamura 
(2008) studied the causes of failure cases in industries to avoid the repetition of failure. Hatamura collected more than 1,000 failure cases, classified the cases from various points of view, and discovered that the failure cases can be classified into a limited number of essential patterns. These patterns could be used to describe the failure cases as well as to transfer the failure knowledge to others. The database has been released on the $\mathrm{Web}$, so anyone can see the details.

\subsection{Patterns from procedures}

User-centered design (UCD) is a standardized methodology for designing products in order to reflect what users can use, want, or need (ISO9241-210 2010). The process includes not only designing a product but also validating its usage in a real situation. It can be identified as iterative cycles of four steps: (1) specify the context of use, (2) specify requirements, (3) create a design solution, and (4) evaluate the design. IDEO, a company renowned for the UCD of its products, services, and environments, proposes the concept of design thinking. The creative methodology is crystallized as IDEO method cards, which are 51 cards from four categories: Learn, Look, Ask, and Try (IDEO 2003). David Kelley, the founder of IDEO, has been teaching design thinking at Stanford design school, where the processes of design thinking are designed in five iterative steps: empathize, define, ideate, prototype, and test. In this process, rapid prototyping plays an important role in driving this cycle. A manual is also a structurally composed pattern of best practices. In the case of customer service, for example, the words and their order of the contact person are carefully determined. By following the manual, necessary information is collected efficiently and reasonably regardless of the skills or performance of contact persons. Design patterns are the patterns for codes, whereas the pattern of practices in programming software is also known as extreme programming (XP) (Beck and Andres 2004). The patterns of XP are defined as 19 practices classified into four types of basic activities (coding, testing, listening, and designing) under five values (communication, simplicity, feedback, courage, and respect).

\section{Shikake triggers}

\subsection{Shikakes as patterns}

As we described in the previous section, a pattern is an essential representation of knowledge and procedures due to its generalized simplicity. To date, shikakes are typically designed by teams of expert engineers and/or designers. However, by applying shikake patterns in design, not only experts but also ordinary people might be able to create new shikakes. A shikake is realized as the combination of physical and psychological triggers. Therefore, a pattern of shikake should be described by combining these types of triggers.

Physical and psychological triggers can be classified into hierarchical categories. However, the categories and the hierarchical structures change depending on the target phenomena perspectives. For example, categories for persuasion (Cialdini 2006) and nudges (Thaler and Sunstein 2009) are different. In this paper, we consider the hierarchical categories of triggers from the shikake perspective. In the following, we first describe the concepts to which we refer for shikake triggers. We then present preliminary shikake triggers that we constructed.

\subsection{Shikake triggers}

Based on these previous studies and practices, we carefully constructed shikake trigger categories to systematically describe physical and psychological triggers as shown in Fig. 7. The hierarchical relations between categories are created based on our analysis of the cases according to our considerations, although interpretations might differ if different viewpoints are considered. The top-level category "Trigger" in Fig. 7 is clustered according to "Physical trigger" and "Psychological trigger" to reflect the idea that a shikake is composed of both physical and psychological triggers. In the following, we explain our considerations by elucidating each of these categories.

\subsubsection{Physical triggers}

The "Physical trigger" category shows the influence realized by a perceivable artifact. Under this category, we assigned second-level categories: Feedback and Feedforward. The Feedback category describes the stimulus received from a shikake in the course of interaction between people and a shikake. The feedback is important to make people understand the progress and achievements, enjoy the interactive process, and behave mindfully rather than mindlessly. The information obtained by the feedback is classified into five categories: Auditory, Haptic, Olfactory, Taste, and Visual.

- The "Auditory" category represents the effect of situation change expressed by the types and rhythms of sound. Sound attracts immediate attention. As we already described, The World's Deepest Bin makes a longer than expected falling sound to attract people's attention (Volkswagen 2009).

- The "Haptic" category represents the effect of stimulus given by forces, vibrations, temperature, and/or 
Fig. 7 Shikake trigger categories

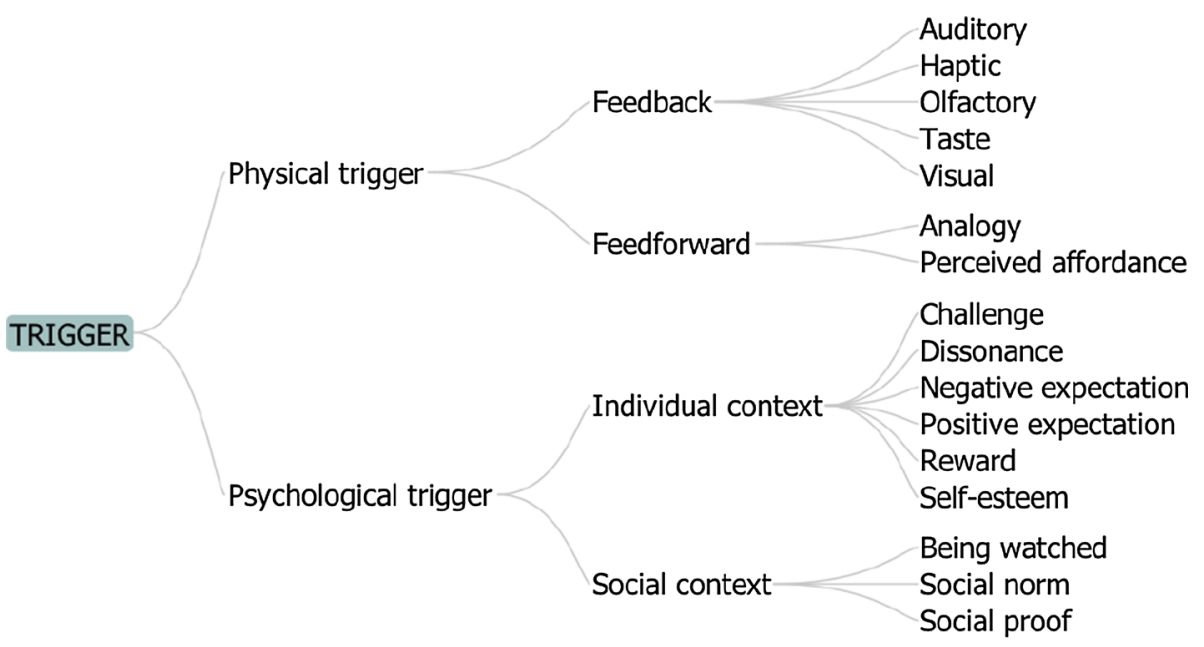

motions to feed back information about targets. For example, when a car runs over a rumble strip on the road, the driver is alerted by the tactile vibration and audible rumbling. The direct feedback works immediately without requiring careful consideration.

- The "Olfactory" category represents the effect of the power of scent that influences people's behavior. For example, city gas in Japan was originally odorless, but a stinky onion scent was purposely added to make people notice gas leaks. Furthermore, smell is strongly associated with our experience of everyday living and can be used as a trigger to set a mood. The scent of fresh waffles, for example, stimulates the appetite of passersby to influence them to purchase the waffles.

- The "Taste" category represents the effect of palate, which makes people aware of the taste. For example, a campaign for mint-flavored parking tickets allows people to experience the flavor of a new product when they drive into a parking lot and put it in their mouth. In this case, the taste stimulus becomes a trigger to make people aware of the flavor (Yamamoto 2013).

- The "Visual" category represents the effect of visualization to make people aware of visible or invisible information. For example, visualization of the number of steps counted by a pedometer (e.g., Fitbit ${ }^{2}$ ) becomes a trigger to encourage people to exercise more. If people set a goal as 10,000 steps/day and they have achieved 7,000 steps, they might push themselves to walk another 3,000 steps.

The "Feedforward" category describes the effect of the perceived characteristics of availability, functionality, and usability acquired from an artifact. The effect becomes a trigger to induce specific behavior either directly or indirectly. The characteristics are realized from the shapes and features of an artifact or the association of our past

\footnotetext{
2 http://www.fitbit.com.
}

experience. This third-level category includes "Analogy" and "Perceived affordance".

- The "Analogy" category involves the use of associations of well-known artifacts in a different context or situation to make people imagine how to use the artifact or what might happen. For example, a tiny shrine gate makes people think of an actual shrine gate, gives people the impression of the surrounding area being holy, and eventually makes them hesitate to litter (see the example in Sect. 4.2).

- The "Perceived affordance" category represents the quality of an object by which people can easily understand how to use or how to behave in a situation (Norman 2010). The perceived affordance is a clue to be interpreted meaningfully whether it is incidental or deliberate. For example, the shape of a door handle gives people the understanding of how to use it, and lines on a parking area guide people to park their bikes between or along the lines.

\subsubsection{Psychological triggers}

Under the "Psychological trigger" category, we identified two subcategories, namely, "Individual context" and "Social context." The "Individual context" category refers to the trigger that directly arouses a positive or negative impulse and includes six third-level categories from extrinsic to intrinsic triggers. Each of these categories describes the following reactions.

- The "Challenge" category describes the trigger that sets an unwritten goal in people's minds. The challenge urges people to become involved, although they do not have to. A fly target in a urinal in Sect. 4.3 offers a challenge to hit it, and men do not easily escape this temptation. 
- The "Dissonance" category indicates that people tend to avoid dissonance. If there is a consecutive picture on the spine of a series of books, people are enticed to put the books in order to see the picture correctly.

- The "Negative expectation" category directly affects our survival instinct to avoid risk, fear, pain, and displeasure. This category is realized by a trigger that makes people perceive negative feelings. For example, a speed bump on a road makes drivers slow down to reduce the shock of impact.

- The "Positive expectation" category is a trigger that arouses people's curiosity by using a shikake to make people excited by imagining what might happen. For example, as we already introduced in Sects. 3.3 and 6.2.1, The World's Deepest Bin provides us with a positive expectation by the longer than expected falling sound. This category is the source of positive feelings such as pleasure, fun, and hope.

- The "Reward" category involves a straightforward approach to providing something valuable in order to encourage people to willingly change their behavior. For example, a free coffee campaign for police officers will increase their visits and eventually improve the security of the establishment. Benefits such as discounts and bonus points are also considered as rewards.

- The "Self-esteem" category represents people's desire rooted in their thoughts, beliefs, and consciousness. People tend to adhere to what is commonly thought of as desirable in terms of logic, rationality, stability, and honesty. For example, transparent trash bins elicit prosocial behavior because people want to maintain their self-esteem (see Sect. 1.2 for details).

The "Social effect" category describes the influences of our social dynamics among others and environments. As we are collaborating, cooperating, and competing with others, we are inherently sensitive to social codes in order to avoid deviating from them. This shikake category includes "Being watched," "Social norm," and "Social proof."

- The "Being watched" category describes the feeling of other people observing you. Detecting eyespots is an innate ability we acquired to survive in the wild, and it can become a powerful trigger to influence people's behavior. In addition to eyespots, we feel like we are being watched due to unfamiliar changes in the environment, for example, blue-colored streetlights and surveillance cameras.

- The "Social norm" category represents the effect of implicitly required standards, manners, or morals from which people are compelled not to deviate. For example, littering in a public space is an undesirable behavior that goes against a social norm.

- The "Social proof" category describes the effect where people assume others' behavior as the correct behavior. As the effect is particularly prominent in ambiguous situations, people follow the same behavior as others to conform to the social proof. The effect also induces what we call the "snowball effect" phenomenon, where a small trigger causes a big change, like a snowball becoming bigger as it rolls down a hill. The same phenomenon is true for people's behavior: a person's behavior change causes others' behavior to change. For example, a long waiting line in a shop becomes a social proof that the shop is popular, so more customers join the line.

\section{Shikake trigger matrix}

We have been collecting hundreds of shikake cases, and we annotated some of them tentatively with the categories shown in Fig. 7. The matrix in Table 1 shows the frequency of physical and psychological triggers simultaneously used in the same shikake cases. The rows and columns represent psychological triggers and physical triggers, respectively, and the numbers are obtained from tagging the 120 shikake cases. These cases consist of the same data used in Matsumura and Fruchter (2013). Note that the sum of the number of cases is not equal to the number of shikake cases, as each shikake case is assigned to as many categories as possible in order to capture the features of a shikake composed of multiple triggers. The shikake cases annotated here are selected at random, and the categories annotated are based on our considerations and interpretations. The 120 shikake cases represent an initial seed to begin testing our conceptual framework. It represents an ongoing effort toward statistically relevant numbers of cases for drawing definite conclusions. Nevertheless, it provides a preliminary insight into shikake.

We assume that the combination of physical and psychological triggers has a synergistic effect that is sufficient to change people's behavior, and this could be an explanation for how a shikake works. Once the typical combinations of triggers employed in many shikake cases are revealed, they become "rules of thumb" in designing new shikake. As seen from the matrix, nonzero numbers are not evenly distributed. Some combinations of triggers were used far more frequently than were others. For example, the combination of "Analogy" and "Positive expectation" was used in 13 shikake cases, and the combination of "Auditory" and "Positive expectation" in 11 shikake 
Table 1 Shikake trigger matrix

\begin{tabular}{|c|c|c|c|c|c|c|c|c|}
\hline & Auditory & Haptic & Olfactory & Taste & Visual & Analogy & Perceived affordance & Sum \\
\hline Challenge & 0 & 0 & 0 & 0 & 9 & 3 & 2 & 14 \\
\hline Dissonance & 4 & 2 & 0 & 0 & 3 & 4 & 5 & 18 \\
\hline Negative expectation & 1 & 3 & 0 & 0 & 4 & 1 & 6 & 15 \\
\hline Positive expectation & 11 & 2 & 1 & 0 & 6 & 13 & 9 & 42 \\
\hline Reward & 1 & 0 & 0 & 0 & 4 & 0 & 0 & 5 \\
\hline Self-esteem & 2 & 0 & 0 & 0 & 5 & 5 & 0 & 12 \\
\hline Being watched & 0 & 0 & 0 & 0 & 5 & 5 & 3 & 13 \\
\hline Social norm & 0 & 0 & 0 & 0 & 0 & 4 & 0 & 4 \\
\hline Social proof & 3 & 0 & 0 & 0 & 1 & 3 & 8 & 15 \\
\hline Sum & 22 & 7 & 1 & 0 & 37 & 38 & 33 & 138 \\
\hline
\end{tabular}

cases. The numbers generally indicate the rules of thumb for finding promising combinations of physical and psychological triggers, as well as an opportunity to explore new trigger combinations leading to novel shikake solutions. Consequently, the low numbers do not represent less usable or possible combinations; they just represent combinations among the 120 analyzed cases.

\section{Conclusion}

Changing behavior has enormous possibilities for creating a better world. A shikake can be an immediate and promising approach to cause behavior change. However, the shikake mechanism was not thoroughly understood, and therefore, it remained difficult to design a new shikake. To tackle this challenge, we assumed that a shikake is composed of physical and psychological triggers where the physical trigger ignites the psychological trigger and the psychological trigger works as a driving force to change behavior. We then proposed shikake trigger categories to describe the physical and psychological triggers to develop systematic shikake specifications. Finally, we presented preliminary results from the analysis of 120 annotated shikake cases to identify trigger combinations and explore rules of thumb in designing new shikake.

Our final goal is to develop a shikake design workshop that allows anyone to create new shikakes. Since 2014, we started to organize a series of shikake design workshops, where the participants are introduced to the shikake triggers to allow them make their own shikakes for solving their own problems. The experience of solving their problems gives participants small but precious confidence that they can change the world. We believe the experience would result in a positive motivation to learn and understand various aspects of life, society, and the environment.
Acknowledgments This work was supported by JSPS KAKENHI Grant Number 24603011.

Open Access This article is distributed under the terms of the Creative Commons Attribution License which permits any use, distribution, and reproduction in any medium, provided the original author(s) and the source are credited.

\section{References}

Alexander C, Ishikawa S, Silverstein M (1977) A pattern language: towns, buildings, construction. Oxford University Press, Oxford Andrews A (2010) The butterfly effect: how your life matters. Thomas Nelson, Nashville

Asch SE (1955) Opinions and social pressure. Sci Am 193(5):17-26

Beck K, Andres C (2004) Extreme programming explained: embrace change, 2nd edn. Addison-Wesley Professional, Reading

Borchers JO (2008) A pattern approach to interaction design. In: Gill $\mathrm{S}$ (ed) Cognition, communication and interaction. Springer, London

Broennimann G (2010) Photo: licensed under Creative Commons Attribution-Share Alike 3.0. http://de.wikipedia.org/wiki/Datei: Urinal_Fly.JPG

Cialdini RB (2006) Influence: the psychology of persuasion. HarperBusiness, New York

Fogg B (2002) Persuasive technology: using computers to change what we think and do. Morgan Kaufmann, Los Altos

Fogg B (2009) A behavior model for persuasive design. In: Proceedings of the 4th international conference on persuasive technology, pp 26-29

Gamma E, Helm R, Johnson R, Vlissides J (1994) Design patterns: elements of reusable object-oriented software. Addison-Wesley Professional, Reading

Hatamura Y (ed) (2008) Learning from design failures. Springer, Berlin

IDEO (2003) IDEO method cards: 51 ways to inspire design. IDEO, Palo Alto

IPROS (2004) Transparent eco-duster catalogue. IPROS Corporation ISO9241-210 (2010) Ergonomics of human-system interaction-Part 210: Human-centred design for interactive systems. ISO

Keizer K, Lindenberg S, Steg L (2008) The spreading of disorder. Science 322(5908): 1681-1685

Matsumura N, Fruchter R (2013) Shikake categories for shikake specifications. In: Technical paper on AAAI2013 Spring Symposium on Shikakeology, pp 68-73 
Milgram S, Bickman L, Berkowitz L (1969) Note on the drawing power of crowds of different size. J Pers Soc Psychol 13(2):79-82

Norman DA (2002) The design of everyday things. Basic Books, London

Norman DA (2010) Living with complexity. The MIT Press, Cambridge

Smets G (1995) Industrial design engineering and the theory of direct perception and action. Ecol Psychol 7(4):329-374

Sullivan LH (1896) The tall office building artistically considered. Lippincotts Mag 57:403-409

Thaler RH, Sunstein CR (2009) Nudge: improving decisions about health, wealth, and happiness. Penguin Books, Baltimore
Tidwell J (2011) Designing interfaces. O’Reilly Media, Sebastopol Volkswagen (2009) The speed camera lottery. The fun theory. http:// www.thefuntheory.com/2009/11/12/fun-theory-award-winnerspeed-camera-lottery

Wilson Q, Kelling GL (1982) Broken windows. Atl Mon 249:29-38

Yamamoto H (2013) Shikakeology and marketing. In: Technical paper on AAAI2013 Spring Symposium on Shikakeology, pp 101-106

Zichermann G, Cunningham C (2011) Gamification by design: implementing game mechanics in web and mobile apps. O'Reilly Media 